\title{
Lexical Collocation Instruction and Its Impact on Iranian Non-academic EFL Learners' Speaking Ability
}

\author{
Zohreh G. Shooshtari \\ Shahid Chamran University of Ahvaz, Iran \\ Nasibeh Karami \\ Shahid Chamran University of Ahvaz, Iran
}

\begin{abstract}
Words do not co-occur haphazardly and in fact lexical patterns are different. This difference in the lexical patterning causes potential problems in speaking. The present study intends to see if receiving treatment on the use of lexical collocations affects the pre-intermediate EFL students speaking proficiency. To achieve this aim, 50 pre-intermediate students of Iran Language Institute, Ahvaz branch were chosen and divided into two groups. In the instruction period of ten sessions, the experimental group received instructions on five common lexical collocation patterns such as Verb+ Adverb, Noun+ Verb, Verb+ Noun, Adverb+ Adjective, and Adjective+ Noun. Both groups took the same test before and after the treatment to measure their knowledge of collocation patterning. They also participated in a speaking task to assess their use of lexical collocation and overall oral proficiency. Results showed that the instruction of lexical collocation had a positive effect on the learners speaking proficiency and a moderate effect on their use of lexical collocations. This suggests that receiving instruction on the use of lexical collocation patterning can be effective in the enhancement of EFL students' language skills, specifically, their oral proficiency.
\end{abstract}

Index Terms - lexical collocation, oral proficiency, vocabulary learning

\section{INTRODUCTION}

Vocabulary learning and its effective use is usually considered as a crucial component in learning languages. Allen (1983, p.5) emphasized that "lexical problems frequently interfere with communication; communication breaks down when people do not use the right words". Krashen (1989, p.440) pointed out that gaining language proficiency entails expanding one's vocabulary stock. Since vocabulary lies at the center of language learning, great attention should be paid to the issues related to vocabulary learning and teaching because without vocabulary enhancement it is difficult to communicate. Reviewing EFL literature reveals that grammar learning received more attention than vocabulary improvement in language classes since before 1970s; that is to say, centrality was given to the mastery of language structure and phonology then.

With the advent of learner and learning-centered approaches to language learning and teaching, language practioners and researchers began to highlight the role of EFL vocabulary acquisition and recommended vocabulary treatment in classroom practices (Channel, 1981; Lewis, 1993; McCarthy, 1984; Nation, 1990; Nattinger, 1980, etc).

This Change of direction from grammar to vocabulary is right. Still, knowledge of collocation which is regarded fundamental to vocabulary acquisition seems to be a neglected area in EFL syllabus design. A collocation in brief, is a pair or group of words that are often used together. Some collocations are fixed or very strong; others are more open and some are not likely to occur; therefore, knowing which words are used together is an important way of understanding the meaning of a text.

Koosha and Jafarpoor (2006,p.2) claim that there is an abundant stock of phrasal and prepositional combinations in English that represent so many collocations, and mastery over them can affect EFL learners' fluency as well as accuracy in both speaking and writing. They further add that the use of lexical collocations is highly correlated with EFL learners' language proficiency.

For many language learners language proficiency equates the development of speaking skill as they believe mastery of oral skills enables them to function better in different social settings and under varied circumstances (Ganji, 2012).

Chastain (1988) argues that speaking has a definite and important place in the language learning. Language teachers should keep in mind that speaking is not a skill, which they can develop in isolation. Increasing speaking skills depends on the input that $\mathrm{L} 2$ learners receive from listening, reading and writing; therefore, by improving the speaking skills we can also help English language students improve their listening, reading and writing.

A number of scholars have suggested that a good command of collocation use can be fruitful in the development of EFL learners' speaking ability. (Ellis \& Schmidt, 1997; Nation, 2001; Nattinger \& DeCarrico, 1992; Schmitt, 2000 among others).This means that language learners are required to develop their knowledge base of word combinations: 
which words are used together and in what patterning. In the same line, this study attempts to examine the Iranian EFL learners' use of lexical collocation instruction and its impact on their speaking proficiency. Our findings may make us more insightful in terms of the effectiveness of lexical collocation familiarity in the development of oral skills. And since the available studies on lexical collocations are set in foreign environment, and not much has been carried out in Iran, this investigation serves to add on to the list of lexical collocations research already carried out.

To pursue the above-mentioned goals, we formulated the following research question:

1. To what extent does the instruction on the use of lexical collocations affect the non-academic EFL learners' speaking proficiency?

\section{BACKGROUND TO THE STUDY}

Research on EFL learners' vocabulary development has mainly focused on the knowledge and production of individual lexical items. However, one main component involved in vocabulary learning, i.e. the problem of word combinability, should be tackled more seriously than before.

It is difficult to form a precise definition of collocations since the definitions are not clearly stated. Still, EFL practioners have defined collocations from different angles while conducting their investigations on word combinability. Lewis (2000) describes collocation as "The way in which words co-occur in natural text in statistically significant ways" (p.1). Nattinger and Decarrio (1992) note that collocations are "strings of specific lexical items that co-occur with a mutual expectancy greater than chance, such as rancid butter and curry favor" (p.36). James (1998) considers collocations as "the other words any particular word normally keeps company with" (p.152).

Baker (1992) divides collocations into grammatical and lexical collocations. Lexical collocations consist of different combinations of, adverbs, adjectives, nouns and, verbs e.g. advanced students, and word combinations which embody an adjective, a noun, or a verb plus a proposition or a syntactic structure like an infinitive or a clause e.g. take off your coat. Wei (1999, p.5), believes that word combinability includes these categories: Lexical collocations, e.g. a serious problem. 2) Grammatical collocations, e.g. tired of and 3) Idiomatic expressions, e.g. feeling under the weather. Hill (2000) proposed four types of word combinations: 1) unique collocations e.g. foot the bill, 2) Strong collocations e.g. moved to tears; 3) Weak collocations e.g. a good weekend and 4) medium-strength collocations, e.g. do the laundry. Benson, Benson and Ilson (1997) used structure type as a norm in grouping of collocations:

1. Verb + Noun such as in tie the rope

2. Adjective + Noun such as in excruciating pain

3. Noun + Verb such as in lions roar

4. Adverb +Adjective such as in completely satisfied

5. Verb +Adverb such as in apologize humbly

6. Quantifier + Noun such as a bit of advice

Biskup (1992) tried to establish whether lexical collocation posed problem for L2 learners and which subtype(s) were particularly difficult. She tested both perception and production. For perception, no difficulty was seen. However, when it came to producing translation equivalent of L1 collocations, students had a lot of problems. Furthermore, it was found that they experienced much difficulty in the production test concerning Verb Noun collocations. From her study, it was concluded that translation engenders L1 transfer in L2 equivalents performance greater than a natural speech situation. To discover the main factors underlying the observed errors in collocation use, she carried out a cross linguistic research to study the performance of EFL learners whose first language tends to be similar (German) or more different (polish) from that language. This was to see if such a distance would greatly affect the production of word combinations in L2.

The sample population was asked to translate their mother tongue collocations into English. Biskup found out that polish students took advantage more from their L1, although, in total, they came up with fewer wrong combinations than in German. It was noticed that polish learners resorted to transfer strategy, while German learners made use of more creative strategies which ended up in committing other kinds of error.

Bahns and Eldaw (1993) examined the knowledge base of German advanced EFL students of Verb Noun collocation. Two groups of German EFL university students consisting of Fifty-eight members were asked to do a translation task embedded in a cloze test. The first group took a cloze test including ten statements each of which had a Verb Noun collocation with a blank space for the verb. The other group worked on a German-English translation test consisting of 15 sentences; the learners were required to translate Verb Noun combinations in each sentence into English. Results showed that only around half of students were able to produce acceptable English collocations. They suggested that in producing correct English, collocations turned out to be a major problem for advanced students.

Tajalli (1994) conducted a contrastive study on the translation of English and Persian collocations and concluded that such learners do not receive adequate exposure to English collocations, so they experience major difficulty in the correct use of them. To sum up, he confirms that English collocations, in general, and their translation into Persian, in particular, require extensive research and that investigations should be geared towards identification, characterization and classification of the more problematic collocations and finding appropriate Persian equivalents for them.

Lien (2003) investigated the relationship between receiving instruction on collocation and reading comprehension. She conducted a quasi-experimental study at a national university in central Taiwan which lasted four-weeks. The participants were 85 Taiwanese college students (i.e., sophomores, juniors, and seniors) majoring in English. In the first 
phase of the study, before reading three different articles of a similar length and difficulty, the learners got involved in three kinds of language practice, namely, vocabulary learning, collocation use and no instruction. Later, they sat for three immediate reading comprehension tests each of which included ten short essay questions. On the basis of findings, she suggested that "collocation instruction had more positive effects on the participants' reading comprehension than vocabulary instruction and no instruction" (as cited in Hsu, J.Y. \& Chiu, Ch.Y. 2008, p.187).

Concerning the speaking skill, Sung (2003) tried to detect the relationship between the knowledge and the use of lexical collocations in relation to speaking proficiency of international students enrolled in a university in Pittsburg area. Participants included 72 non-native English speakers. They completed two tests. The first test assessed the subjects' knowledge of lexical collocation; the second measured the learners' use of lexical collocations and their speaking proficiency. The results indicated a significant correlation between the knowledge of lexical collocations and the students' speaking ability (as cited in Hsu, J.Y. \& Chiu, Ch.Y. 2008, p.185).

Hsu (2005) explored the impact of explicit collocation instruction on EFL learners listening comprehension. To achieve the purpose of the study, thirty-four Taiwanese university students were invited to take part in this research. Over a three-week period, each student received three various kinds of practice including single-item vocabulary practice, lexical collocation instruction and no treatment; later, one listening comprehension test was administered after each type of instruction. After four weeks, the participants completed a questionnaire. The results revealed that the learners performed best after receiving lexical collocation instruction. In addition, in response to the questionnaire items, the students pointed out that the collocation instruction was their preferred instruction type and that they were motivated to learn more about lexical collocations; finally, they noted that receiving treatment on lexical instruction improved their listening ability.

Mahmoud (2005) worked on the collocation errors which Arab learners of English committed when practicing collocation use. After data analysis, a total of 420 collocations were tracked in 42 essays written by Arab speaking university students majoring in English. Descriptive statistics revealed that about $64 \%$ of collocations used were wrong and $80 \%$ of these were lexical collocations compared with grammatical ones. He also noted that $61 \%$ of the incorrect combinations could be attributed to negative transfer from Arabic.

Ghonsooli, Pishgaman and Mahjoobi (2008) investigated the interplay between collocation instruction and the development of the writing skill of Iranian EFL learners. Thirty participants from the English Department of Ferdowsi University were involved in the study. The data gathered were analyzed both quantitatively and qualitatively. Results showed considerable promotion in the students' writing performance in terms of vocabulary gain and fluency due to familiarity with collocation use.

Hsu and Chiu (2008) investigated the impact of familiarity with English collocation use on the speaking ability of Taiwanese EFL university learners. Data for the study was collected from 56 junior English majors' performance on word combinability. These students were required to take three tests: (1) one lexical collocation test (2) one English speaking test and (3) phone pass spoken English test. The results indicated a significant correlation between Taiwanese EFL learners' knowledge of lexical collocations and their speaking proficiency. However, no significant correlation was found between the subjects' use of lexical collocations and their language oral skill. There was also no statistically significant correlation between the subjects' knowledge and use of lexical collocations. More detailed, it was suggested that familiarity with lexical collocations appears to be a better predictor of the learners' speaking proficiency than their ability to use lexical collocations.

In another study, Hsu (2010) tried to find out if direct collocation instruction influences EFL learners' reading comprehension and vocabulary learning. Based on three academic levels, three groups of Taiwanese college English majors participated in the study. They were exposed to three kinds of treatment: single-item vocabulary instruction, lexical collocation instruction, and no treatment. Afterwards, the participants took a reading comprehension test and 3 vocabulary recall tests. The results analyzed quantitatively, revealed that the lexical collocation instruction has a positive effect on the learners' vocabulary gain more than their reading comprehension across all three academic levels.

As mentioned earlier, various studies have been conducted with regards to the impact of familiarity with collocation use on the improvement of language proficiency in different skills. Yet, to the best of our knowledge, no study has been done in Iranian non-academic setting concerning the effect of the lexical collocation awareness on the development of EFL learners' oral proficiency. Hoping to fill this gap, the present investigation sets out to add empirical support, in relation to the impact of knowledge of collocation patterning on the speaking ability of EFL learners, to the existing literature on collocation.

\section{METHODOLOGY}

\section{A. Participants}

This investigation was conducted at Iran Language Institute (ILI), Ahvaz branch. From among 162 participants who took the ILI placement test (Nick, et al, 2006), 50 pre-intermediate female students with the age range of 20 to 35 were chosen to take part in the study. They were randomly assigned to two experimental and control groups each including 25 learners.

\section{B. Instrument}


A lexical collocation test (Appendix A) was used as one of the required instruments in this study. The test included 20 multiple- choice items, 20 fill-in-the-blank without choice, five with choice, and an open ended question in which they had to choose 10 out of 15 words given in writing a paragraph on the related topic. The test items were culled from Oxford Collocation Dictionary (2002), and Cambridge English Collocation in use (2005), and it was meant to evaluate the EFL learners' familiarity with word combinability. The same test was administered before and after the treatment program. The next instrument used in the study was a speaking activity. The participants performed the task once at the beginning, before taking the lexical collocation pre-test and once after taking the post-test. They were given a list of ten topics (Appendix B) and almost two minutes to choose two topics to think about before expressing their views. Efforts were made to pose varied questions on different topics so that more natural conversation could be elicited.

\section{Procedure}

To conduct the study, a set of procedures were ensued as follows: Firstly, fifty female students from Iran Language Institute, Ahvaz branch, took part in the study and were split up into experimental and control groups, each including 25 subjects. The pre-test was administered in the first session at the commencement of the study. The test required approximately 50 minutes for completion. In rating the test item responses, a correct answer received one mark and the wrong answer was marked " 0 " However, no mark was deduced for erroneous responses.

Having got through with the pre-test on lexical collocations, both groups participated in the speaking activity in which they were asked to express their views on two topics of their own choice among from ten topics presented to them. Then, their speaking was rated based on Hughes (2003) checklist with addition of a collocation section.

The treatment period consisted of 10 thirty minute sessions. One session, they were taught lexical collocation in addition to their course book material with examples and the other session they were given fill-in-the-blank tests. Afterwards, the various answers that could be given to that test were offered for more practice. This continued over the ten session treatment period while only the course book materials were presented to the control group. To establish fidelity of treatment, other conditions (the teacher, and class period) for the groups were the same. The classes were held two sessions a week and the whole treatment lasted for about 7 weeks.

Both groups of participants sat for the post-test which was administered approximately a week after the end of the treatment sessions. The procedures for administering the post-test strictly resembled those of the pre-test stage; then, the results were compared, analyzed, and interpreted against the pre-test.

Prior to the administration of the pre-test, a 45-item test, comprising 20 multiple choice and 25 fill-in-the-blanks and an open ended question focusing on lexical collocation was designed by the researchers as a pre- and a post test. Then the test items were piloted on a small randomly selected sample of pre-intermediate students from Iran Language Institute. The test was also inspected closely for face and content validity by two experts with high expertise in the area of language testing and teaching. The performed reliability analysis encompassed item difficulty and item discrimination, running KR-21 method; the reliability quotient was tallied to be 0.75 . The total test, thus, proved to be at an appropriate and acceptable level of reliability (Hughes, 2003; p.38).

After the post-test, again the participants took part in the oral activity to evaluate their oral language performance in terms of the demonstration of collocation use. Then, their speaking performances- both before and after treatment- were rated based on Hughes (2003) checklist with addition of a collocation section. Their speaking performances were recorded and rated by two raters, once by one of the researchers and then by an EFL instructor.

\section{RESULTS}

In the first phase of data analysis the participants' performances on the pre-test and speaking task was examined. The results are presented in tables one and two below:

TABLE 1.

\begin{tabular}{|l|l|l|l|l|l|}
\multicolumn{7}{c}{ LEARNERS' MEAN SCORES ON LEXICAL COLLOCATION PRE-TEST } \\
\hline Group & Stage & Mean & Number & Standard Deviation & Standard Error Mean \\
\hline Control & Pre-test & 15.32 & 25 & 4.14 & 0.82 \\
\hline Experimental & Pre-test & 15.72 & 25 & 5.90 & 1.18 \\
\hline
\end{tabular}

TABLE 2.

RESULTS OF INDEPENDENT T-TEST FOR THE TWO GROUPS' PERFORMANCE ON THE LEXICAL COLLOCATION PRE-TEST STAGE

\begin{tabular}{|l|l|l|l|l|l|l|}
\hline Stage & Group & Mean Difference & Std. Error & $t_{\text {observed }}$ & d.f & Sig (2-tailed) \\
\hline Pre-test & Control-Experimental & 0.40 & 1.44 & 0.27 & 48 & $\mathrm{~ns}$ \\
\hline
\end{tabular}

Table 2 indicates insignificant difference between the mean scores of two groups (control: 15.32; experimental: 15.72) at the pre-test stage. The T-observed value $(0.27)$ turned to be less than the value of T-critical $(0.277<2.021)$, meaning that in terms of the lexical collocation test, the two groups were homogeneous at the start. Tables three and four display the descriptive statistics run on the scores of speaking activity conducted before instruction period. 
TABLE 3.

LEARNERS' MEAN SCORES ON THE SPEAKING ACTIVITY BEFORE THE TREATMENT PERIOD

\begin{tabular}{|l|l|l|l|l|l|}
\hline Group & Stage & Mean & Number & Standard Deviation & Standard Error Mean \\
\hline Control & Pre-test & 21.52 & 25 & 3.77 & 0.75 \\
\hline Experimental & Pre-test & 22.44 & 25 & 3.55 & 0.71 \\
\hline
\end{tabular}

TABLE 4.

RESULTS OF INDEPENDENT T-TEST FOR THE TWO GROUPS' PERFORMANCE ON THE SPEAKING ACTIVITY BEFORE THE TREATMENT PERIOD

\begin{tabular}{|l|l|l|l|l|l|l|}
\hline Stage & Groups & Mean difference & Standard Error & $t_{\text {observed }}$ & d.f & Sig(2-tailed) \\
\hline Pre-test & Control-Experimental & 0.92 & 1.03 & 0.88 & 48 & $\mathrm{~ns}$ \\
\hline
\end{tabular}

Table 4 displays the results of the students' performance on pretest oral task, which indicates similarity between the mean scores obtained by control and experimental groups. The T-observed value $(0.88)$ was much less than that of the T-critical $(0.88<2.02)$, indicative of homogeneity between control and the experimental groups in terms of speaking proficiency. Thus, the researchers felt confident about the existence of no significant gains in lexical collocation between the two groups before the onset of instruction program.

After the treatment, the next step taken was to detect any noticeable change which probably occurred in the performance of the experimental group who received instruction in lexical collocation. In so doing, the results of the performances of the two groups on lexical collocation were compared. Tables 5 and 6 illustrate this analysis.

TABLE 5.

THE LEARNERS' MEAN SCORES ON THE POST-TEST LEXICAL COLLOCATIONS

\begin{tabular}{|l|l|l|l|l|l|}
\hline Groups & Stage & Mean & Number & Standard Deviation & Standard Error Mean \\
\hline Control & Post-test & 12.40 & 25 & 2.54 & 0.50 \\
\hline Experimental & Post-test & 22.00 & 25 & 5.97 & 1.19 \\
\hline
\end{tabular}

TABLE 6.

RESULTS OF INDEPENDENT T-TEST FOR THE TWO GROUPS' PERFORMANCE ON THE LEXICAL-COLLOCATION POST-TEST STAGE

\begin{tabular}{|l|l|l|l|l|l|l|}
\hline Stage & Group & Mean Difference & Std. Error & $t_{\text {observed }}$ & df & Sig(2-tailed) \\
\hline Post-test & Control-Experimental & 9.60 & 1.30 & 7.38 & 48 & 0.00 \\
\hline
\end{tabular}

The results of the independent T-test on the lexical collocation at the Post-test stage-as shown in table 6- revealed that $\mathrm{T}$-observed $=(7.38)$ in this stage, exceeds $\mathrm{T}$-critical $=(2.02 ; \mathrm{P}<0.05)$. The mean score difference between the two groups in the post-test administration is 9.60; this suggests a higher performance on behalf of experimental group compared with the control group. Tables 7 and 8 display the results of two groups' performance on post-stage speaking activity.

TABLE 7.

LEARNERS' MEAN SCORES ON POST- TREATMENT SPEAKING ACTIVITY

\begin{tabular}{|l|l|l|l|l|l|}
\hline Group & Stage & Mean & Number & Std. Deviation & Std. Error Mean \\
\hline Control & Post-test & 21.40 & 25 & 4.17 & 0.83 \\
\hline Experimental & Post-test & 23.76 & 25 & 3.33 & 0.66 \\
\hline
\end{tabular}

TABLE 8.

RESULTS OF INDEPENDENT T-TEST ON THE TWO GROUPS' PERFORMANCE ON THE POST-TREATMENT SPEAKING ACTIVITY

\begin{tabular}{|l|l|l|l|l|l|l|}
\hline Stage & Groups & Mean difference & Standard Error & $t_{\text {observed }}$ & $\mathrm{df}$ & Sig(2-tailed) \\
\hline Post-test & Control-Experimental & 2.36 & 1.06 & 2.20 & 48 & 0.03 \\
\hline
\end{tabular}

A significant difference was discovered via the statistical procedure of t-test between both groups performance on the post oral activity ability. Table 8 shows that the magnitude of $t$-observed exceeded $t$-critical value $(\mathrm{t}$-observed $=2.20>\mathrm{t}-$ critical $=2.021$ ) at the 0.05 probability value. It cab be concluded that lexical collocation practice exerted a great impact on the improvement of experimental groups speaking skill.

To determine if, after receiving the special treatment, any change appeared in the collocation knowledge of the learners in general, and those who received instruction in particular, the performance of each group on collocation test at the pretest stage was compared with its performance at the posttest stage.

TABLE 9.

RESUltS OF MATCHED T-TEST ON GROUPS' COLLOCATION PERFORMANCE AT THE PRE-TEST AND POST-TEST STAGES

\begin{tabular}{|l|l|l|l|l|l|}
\hline \multirow{2}{*}{ Group } & Mean & \multirow{2}{*}{ Number } & \multicolumn{2}{|l|}{ Standard Deviation } \\
\cline { 2 - 3 } \cline { 5 - 5 } & TPRE & TPOST & & TPRE & TPOST \\
\hline Control & 15.32 & 12.40 & 50 & 4.14 & 2.54 \\
\hline Experimental & 15.72 & 22.00 & 50 & 5.90 & 5.97 \\
\hline
\end{tabular}

As table 9 reveals, there was a prodigious increase in the mean score of the experimental group after the treatment (from 15.72 to 22.00). A decrease was observed in the mean score of the control group (from 15.32 to 12.40). These fluctuations are indicative of the fact that the experimental group made progress in vocabulary knowledge from the pretest to the post-test stage, while the control group did not. 
To further ensure and determine if, after receiving the specific treatment, any significant improvement appeared in the speaking ability of the learners in general, and the experimental group in particular, the results of the each group performance on oral activity was compared at pre-test and the post-test stage through applying the paired T-test as presented in the following table.

TABLE 10 .

RESUlTS OF MATCHED T-TEST ON GROUPS' SPEAKING PERFORMANCE AT THE PRE AND POST-TREATMENT STAGES

\begin{tabular}{|c|c|c|c|c|c|}
\hline \multirow[t]{2}{*}{ Group } & \multicolumn{2}{|l|}{ Mean } & \multirow[t]{2}{*}{ Number } & \multicolumn{2}{|c|}{ Standard Deviation } \\
\hline & TPRE & TPOST & & TPRE & TPOST \\
\hline Control & 21.52 & 21.40 & 50 & 3.77 & 4.17 \\
\hline Experimental & 22.44 & 23.76 & 50 & 3.55 & 3.33 \\
\hline
\end{tabular}

As table 10 indicates, there was an increase in the mean score of the experimental group after the treatment (from 22.44 to 23.76), but it was not much significant. Moreover, no great change was observed in the mean score of the control group (from 21.52 to 21.40). This indicates that the experimental group made progress in speaking though not stupendous.

\section{DISCUSSION}

The present study, as stated before, intended to find out if the instruction on lexical collocations affects the students' knowledge of these constructions and their speaking proficiency. According to the overall results of data analysis, a positive relationship was detected.

The results in the previous section showed that the teaching of lexical collocations, at least at the pre-intermediate level, helped the students improve their familiarity with lexical word combinations and used them in their oral practice. The findings of this study seems to match those drawn from the previous studies on lexical collocation instruction which have shown the positive effect of such instruction on the improvement of students' language skills, like reading (Hsu2010), listening (Hsu, 2005) and writing (Liu, 1999, Ghonsooli, Pishgaman \& Mahjoobi, 2008)

With regard to the use of word grouping in the oral activity, the researchers came to this point that lexical collocation instruction had exercised a moderate effect on the correct use of collocation patterning by the participants while expressing their views orally. Several possible explanations are drawn from this fact. Probably, this may be attributed to the influence of learners' native language, here Persian. Using "color spreads" instead of "color runs" can possibly be the sign of the learners L1 influence.

Second language learners often rely on their native language in trying to communicate. They think that there exists a one-to-one correspondence between L1 and L2 lexical items. This might be of some help to the learners, but it is also a major cause of errors because even equivalent lexical items do not always convey the same meaning in two languages for various reasons including cultural differences which can be seen in the vocabulary of every language. This false assumption causes the learners to use L2 lexical items inappropriately. Even after the learners have mastered single lexical items, they still face difficulty using it properly, especially in uncontrolled speech because they haven't still learned which words go together, So mother tongue influences the way learners comprehend the collocation relations between words and expressions and the way they collocate words in L2.

Martelli (1998) notes that L1 transfer may explain this misunderstanding and the production of incorrect word combinations. In the same line, Shalev (2000) contends that EFL learners would use collocations wrongly in case their mother tongue is different from English. If the role of subjects' first language in choosing collocations is investigated, we would observe instances of first language influence. Since in this study we are not sure if cross linguistic influence in terms of typological distance happened in its true sense, similarity is considered an influence. For example, data analysis in the current study revealed that two students used the expression "new vegetables" instead of "raw vegetables". Here, native language transfer may be suggested as the source of error because in Persian the expression "sabzijate tazeh" is frequently used.

The assumption that learners mother tongue is of influence on collocation is shown in the study by Biskup (1992) in relation to the strategy of transfer (positive and negative). Although EFL learners assume that there is a one-to-one correspondence between L1 and L2, transfer sometimes ends up in correct collocating. That is, L1 transfer may be helping the students in choosing the proper collocates. For example, some of the students used "enough time", for "zamane kafi", "good smell", for "booye khoob", and "traditional food" for "ghazaye sonati".

It can also be argued that learners usually learn L2 words in single format, without attending to ways through which words group together. EFL learners in various proficiency levels often know the words in isolation, but they frequently use them inaccurately in combinations. Hill (1999) explains that most learners with "good vocabulary items" have problems with fluency because their 'collocation competence' is very limited.

Lack of cultural competence might be another factor which prevents learners from producing collocations which are colored culturally. Teliya and Brayina (1998, p.170) claim that there exist limitation on using some word combinations which are culture-specific. The problem is that the culture of the source and target language is different so a source language collocation may not exist in the target language culture at all; i.e., "Sunday dinner" which is "nahare makhsoose rooze yekshanbe". 
And the last but not the least reason might be rooted in the fact that students use avoidance strategies when speaking which means they avoid using difficult word or structures, and will use a simpler word or structure instead. While speaking in the current study, it was seen that the students tried hard to use easier lexical collocation types which in this case was $(\operatorname{Adj}+N)$ so that they could speak more frequently. the learners in this study used Adj+N subtypes more than the other types; the likely explanation might be that they have the same structure but reversed (N+Adj) in their native language and that they have become familiar with this structure from the beginning levels of learning English; furthermore, the teachers have taught the students this structure by 'contrastive analysis' which means contrasting it with their mother tongue (included in Iran Language Institute teaching curriculum).

One mentionable finding drawn from this research is that, from among the subtypes, the subjects showed the most improvement in learning $\mathrm{ADJ}+\mathrm{N}$ subtypes and the least in learning ADV+ADJ subtypes. It can be argued that the structure $\mathrm{ADV}+\mathrm{ADJ}$ is not a frequent pattern in their mother tongue and usually not used so; they have not been exposed to this structure before and, now that they learn it, because they cannot associate it with their mother tongue, they prefer to avoid it. Another reason might be that they have not learned it well during the instruction.

Overall, as indicated in table 10, lexical collocation instruction improves students speaking proficiency though not significantly. This improvement might be attributed to the fact that by learning these collocations and becoming aware of the relationship between the words, they could use words better with their associations in their speech. This is in line with what Ying and Hendrick (2004) call awareness-raising.

\section{CONCLUSION}

In the present study, the analysis of the data revealed that the instruction of lexical collocations affected the EFL learners' proficiency positively and the findings further reflected that the treatment had been effective on the use of lexical collocations, though not to a great extent, which might be justified in terms of native language influence, learning collocations in isolation, cultural interference, and avoidance strategies. The analysis also revealed that among sub-classes of lexical word groupings, examined, Adjective+ Noun combinations were easier to use and Adverb+ Adjective collocations were the most difficult.

In broad terms, the students should be made aware of collocations and their subcategories and be given the opportunity to practice collocations in natural situations. Logically, it can be suggested that awareness raising on word collocating turns to be essential for having a good command of English. Furthermore, the teaching of collocations needs to be integrated with the teaching of vocabulary. In addition, dictionaries on collocations can foster the development of collocation competence by providing examples of lexical items with different collocates, highlighting the subtle distinctions between collocations that appear to be structurally similar.

As for pedagogical implications, it is suggested that vocabulary instruction be done through presenting words in collocations. If the students are presented with the words more frequent collocates, they will be less likely to make odd and erroneous word combinations. Gitsaki (1996) suggests that language teachers should introduce items with their most frequent collocations. Furthermore, by exploring the main areas of problems that the learners have with regard to collocations, teachers can identify and then classify the most problematic types of collocations and emphasize them more in their curriculum.

\section{ApPendix A SAmple Used PRE AND POSt TeST}

\section{A: Use the italicized words in answering the questions.}

1. Complications will ........... if the drug is not used properly.
a) advance
c) happen
b) spread
d) develop

2. Twenty five girls were hostage for four months.
a) confined
c) kept
b) held
d)grasped

3. I've had this ............headache ever since I woke up this morning.
a) potential
c) constant
b) dominant
d) primitive

4. The students repeated the sentences after the teacher
a) extremely
b) heavily
c) immediately
d) hungrily

5. He behaved ...........although the rainy weather canceled his going to picnic.
a) angrily
b) agreeably
c) disappointedly
d) hurriedly

6. When he came to the party he looked
a) madly
b) fairly
c) little
d) much

7. I like all her novels, but the latest one is good. Everybody has to read it. 

a) chiefly
c) firstly
b) particularly
d) originally

8. Sara ......cold, developed pneumonia and died.
a) caught
c) got
b) attracted
d) acquire

9. I felt ..happy when I heard of your success.
a) expressively
c) collectively
b) actively
d) decidedly

10. David Lawrence's mother was the influence in his life.
a) temporary
c) dominant
b) primitive
d) constant

11. Whenever I have to leave home.
a) hurriedly
b) really
c) obviously

I forget to take my watch.
a) ceased
b) arrested
c) released
d) trusted

12. 200 people lost their jobs when the company

13. It is raining
a) carefully
c) heavily
b) obviously
d) weakly

14. I was tired when I got home.
a) correctly
b) extremely
c) closely
d) hopefully

15. It was unusual to see David ......faced and nervous.
a) pasty
b) untidy
c) $\mathrm{mad}$
d) minor

16. The clock on the table Twelve o'clock.
a) said
c) pronounced
b) announced
d) suggested

17. Her horizons didn't
a) stretch
b) expand
c) extend
d) spread beyond his next night out.

18. You must ..........your own feelings and decide for yourself.
a) grow
c) trust
b) raise
d) heal

19. He is a ........smoker. That's why he always stinks of smoke.
a) hard
c) big
b) heavy
d) strong

20. This color
a) stretches
b) runs
c) spreads
d) extends

so wash the shirt separately.

B: Fill in the blanks with proper collocations.

21. Her work includes the local rainfall.

22. She placed her keys .......... on the table and sat down.

23. For nearly two months the fighting

24. Are you ........ aware of the implications of your action?

25. She took a ......... Fall while out riding.

26. The doctor ordered him to take exercise.

27. Hopes of a peace settlement were fading

28. He has been asked to .......... a presentative about his work.

29 . The prisoner was hanged for $\ldots \ldots \ldots \ldots \ldots \ldots$ murder.

30. A lot of effort .......... making the costumes.

31. We entered a ........... decorated room.

32. Everything in the room was ......... dirty.

33. The morning ........... blue sky and golden clouds.

34. They rode ........... all night.

35. Do I ........ a hint of jealousy in your voice?

36. Invading that country was a/an ........ Stupid thing to do.

37. Will we ever find out why the disaster.

38. Mary whispered in john's ear. 
39. The titanic sank on it's voyage.

40. He was twisting on the ground in ......... pain.

C: Fill in the blanks with the words given.

warmly major filled merged proudly

41. She ............. the box with old clothes.

42. Nadya Smiled ............. as she watched the children playing happily in the garden.

43. Unemployment is a .............. problem for the government at the moment.

44. My grandparents have been married for forty five years.

45. The two companies .............. in 2003 and now form one very large corporation.

D: Write a paragraph about the food you like and dislike with ten of the words given below.

tasty; starchy; chew; cheap; rich; smell; canned; contain; quality; taste; junk; raw; price; vegetable; traditional

\section{APPENDIX B ORAL ACTIVITY TOPICS}

1. If you could start your life again, would you do anything differently?

2. How do you see yourself in ten years time?

3. Are you going to bring your child up any differently to the way your parents did?

4. If you are asked to talk about your family, how would you describe each member?

5. How have weddings changed in recent years?

6. Talk about yourself, your likes, dislikes characteristics, style, etc...

7. Describe the best place you have ever been.

8. Talk about your ideal home.

9. What are your plans for this summer?

10. Talk about anything you want.

\section{REFERENCES}

[1] Allen, V.F. (1983). Techniques in teaching vocabulary. Oxford: Oxford University Press.

[2] Bahns, J. \& Eldaw, M. (1993). Should we teach EFL students collocations? System, 21(1), 101-114.

[3] Baker, M. (1992). In other words. London: Routledge.

[4] Benson, M., Benson, E, \& Ilson, R. (1997). The BBI dictionary of English word combinations. Amesterdam: John Benjamins Publication Company.

[5] Bisk up, D. (1992). L1 influence on learners rendering of English collocations: a Polishe/German empirical study. In P.J.L. Arnoud \& H. Bejoint (Eds.), Vocabulary and applied linguistics (pp.85-93). London: Macmillan Academic and Professional.

[6] Channel, J. (1981). Applying semantic theory to vocabulary teaching. English Language Teaching Journal, 35, 115-122.Ltd.

[7] Chastain, K. (1988). Developing second-language skills: Theory and practice. Virgiana: Harcourt Brace Jovanovich.

[8] Ellis, N. C. \& Schmidt, R. (1997). Morphology and longer distance dependencies: Laboratory research illuminating the A in SLA. Studies in Second Language Acquisition, 19, 145-171.

[9] Ganji, Mansour.(2012) "The Effects on Reading Comprehension of Lexical Collocation Instruction, Subject Matter Knowledge, and Cultural Schema", Theory and Practice in Language Studies, 2,(1), 105-112.

[10] Ghonsooli, B., Pishgaman, R. \& Mahjoobi, F. (2008). The impact of collocational instruction on the writing skill of Iranians EFL learners: A case of product and process study. Iranian EFL Journal, 2, 36-59.

[11] Gitsaki, C. (1996). The development of ESL collocational knowledge. A thesis submitted for P.H.D. in the center of language teaching and research at the University of Queensland. www.cltr.uq.oz.au:8000/users/christia.gitsaki/thesis/contents.html. (accessed 15/7/2010).

[12] Hill, J. (2000). Revising priorities: from grammatical failure to collocational success. In M. Lewis (Ed.), Teaching Collocation (pp.47-70). Hove: Language Teaching Publications.

[13] Hsu, L. C. (2005). The effect of lexical collocation instruction on Taiwanese college EFL learners listening comprehension. Unpublished master thesis, National Kaohsiung First University of Science and Technology, Taiwan.

[14] Hsu, J.Y. \& Chiu, Ch.Y. (2008). Lexical collocations and their relation to speaking proficiency of college EFL learners in Taiwan. Asian EFL Journal, 10(1), 181-204.

[15] Hsu, J.Y. (2010). The effects of collocation instruction on the reading comprehension and vocabulary learning of Taiwanese college English majors. Asian EFL Journal, 12(1), 47-87.

[16] Hughes, A. (2003). Testing for language teachers. Cambridge: Cambridge University Press.

[17] Koosha, M. \& Jafarpour, A. (2006). Data-driven learning and teaching collocation of prepositions: The case of Irainian EFL adult learners. Asian EFL Journal, 8(8), 1-14.

[18] Krashen, S. (1989). We acquire vocabulary and spelling by reading: additional evidence for the input hypothesis. The Modern Language Journal, 73, 440-464.

[19] Lea, D. (2002). Oxford collocation dictionary. Oxford: Oxford University Press.

[20] Lewis, M. (1993). The lexical approach: the state of ELT and a way forward. Hove: Language Teaching Publications.

[21] Lewis, M. (2000). Teaching collocation: further development in the lexical approach. Hove: Language Teaching Publications.

[22] Liu, C. P. (1999). An analysis of collocation errors in EFL writings. The proceedings of the $8^{\text {th }}$ international symposium on English teaching, Taipei: Crane.

[23] Mahmoud, A. (2005). Collocation errors made by Arab learners of English. Asian EFL journal, 2, 1-10. 
[24] Martelli, A. (1998). Lexical errors in EFL writing: a corpus-based approach. In J.Beekman (Ed.), Learning to write in a second language (pp.69-107). Cambridge: Newbury House.

[25] McCarthy, M. J. (1984). A new look at vocabulary in EFL. Applied Linguistics, 5(1), 12-22.

[26] McCarthy, M., O'Dell, F. (2005). English Collocation in use. Cambridge: Cambridge University Press.

[27] Nation, I. S. P. (1990). Teaching and learning vocabulary. New York: Newbury House.

[28] Nation, I. S. P. (2001). Learning vocabulary in another language. Cambridge: Cambridge University Press.

[29] Nattinger, J. (1980). A lexical phrase grammar for ESL. TESOL Quarterly, 14(3), 337-344.

[30] Nattinger, J. \& DeCarrio,J. (1992). Lexical phrases and language teaching. Oxford: Oxford University Press.

[31] Nick, et al. (2006). Iran Language Institute Placement test. Unpublished placement test. Tehran: Iran Language Institute.

[32] Schmitt, N. (2000). Vocabulary in language teaching. Cambridge: Cambridge University Press.

[33] Shalev, N. (2000). Collocations. In J. Morley (Ed.), Current prespective on language learning. (pp.105-141). New York: Greenwood Press.

[34] Tajalli, G. (1994). Translatability of English and Persian collocations. Tabriz: Tabriz University Publications.

[35] Teliya, V. \& N. Bragina. (1998). Phraseology as a language of culture: its role in the representation of a collective mentality. In A.P. Cowie (Ed.), Phraseology, Theory, Analysis and Applications (pp.161-186). New York: Oxford University Press.

[36] Wei, Y. (1999). Teaching collocations for productive vocabulary development. Paper presented at the annual meeting of the teachers of English to speakers of other languages. New York.

Zohreh G. Shooshtari received her PhD degree in applied linguistics from Esfahan University, Iran in 2007. She is an assistant professor presenting courses in language testing, language teaching methodology, syllabus design and advanced writing and reading at the department of English language and Literature of Shahid Chamran university of Ahvaz, Iran. Her area of research interest includes second language acquisition, academic reading and writing, discourse analysis and syntactic argumentation. She has presented and published nationally and internationally on issues related to her main area of research interest.

Nasibeh Karami received her M.A in language teaching methodology in 2010. She is teaching general English language courses at Iran Language Institute (ILI).Her main area of interest includes issues related to second language learning and teaching namely vocabulary learning, L2 reading and listening strategies. 